\title{
Research on a Segmentation and Evaluation Method Combining Tooth Morphology Features
}

\author{
Investigación sobre un Método de Segmentación y Evaluación \\ que Combina Características Morfológicas Dentales
}

\author{
Huifang Yang ${ }^{1,2,3,4,5} \&$ Siwei Wang ${ }^{4,5,6}$
}

YANG, H. \& WANG, S. Research on a segmentation and evaluation method combining tooth morphology features. Int. J. Morphol., 38(5):1325-1329, 2020.

SUMMARY: To explore a new semi-automatic method to segment the teeth from the three-dimensional volume data which acquired from cone beam computed tomography (CBCT) scanner. Scanned dental cast models are used to evaluate the segmentation accuracy. The CBCT data are loaded to ORS software. Based on gray value, a semi-automatic method was used to segment teeth and then the segmented teeth were saved in STL format data. Smooth the mesh data in the Geomagic Studio software. The upper and lower dental cast models were scanned by a white light scanner and the data was saved in STL format too. After registering the model data to teeth data, the deviation between them was analyzed in the Geomagic Qualify. All teeth could be obtained, the method is simple to use and applied in orthodontic biomechanics. The entire process took less than 30 minutes. The actual measured Root Mean Square (RMS) value is $0.39 \mathrm{~mm}$, less than $0.4 \mathrm{~mm}$. This method can segment teeth from the jaw quickly and reliably with a little user intervention. The method has important significance for dental orthodontics, virtual jaw surgery simulation and other stomatology applications.

KEY WORDS: Cone beam computed tomography; 3D scanner; Segmentation; Digital orthodontics.

\section{INTRODUCTION}

Cone-beam computed tomographic (CBCT) was first introduced to dentistry in Europe since 1998 and approved for the clinical use in the USA in 2001 (Kapila \& Nervina, 2015). CBCT imaging has been proved to be a valuable tool in dentistry and been utilized for diagnosis, treatment planning and research (Merrett et al., 2009; Shahbazian et al., 2013; Park et al., 2015). CBCT scanner has been used in the fields of oral surgery, endodontics, orthodontics and prosthodontics (Porciúncula et al., 2014; Liebregts et al., 2015; John et al., 2016). CBCT images could be displayed in sagittal, axial and coronal planes for viewing teeth, bone, temporomandibular joint and other tissues.

Orthodontic treatment involves complex tooth movements in three-dimensional directions. Tooth root morphology, size and location are important for orthodontists. Using CBCT images, the anatomical information of mandibular canal, root and crown can be reconstructed (Kovisto et al., 2011).
In addition, physicians would be able to perform more accurate treatments with the help of CBCT images, and keep the periodontal tissues healthy, or maintain crowns and roots in their new positions after the treatment. Without being given consideration, the dental root may move out of the bone cortex during or after the treatment (Cheng et al., 2015). Therefore tooth segmentation was important for Orthodontic.

The tooth segmentation is a challenging work, as the lack of margins in the crown in CBCT images. Due to the noise of the image or the distribution density of the root and alveolar images are similar, it is difficult to segment the root (Gan et al., 2015). Heo \& Chae (2004) performed a toothby-tooth segmentation using the region growing algorithm, where the reference slice was first selected from CT slices and tooth segmentation was then carried out interactively based on shape characteristics of each tooth. The size, location and intensity of corresponding tooth were very similar, so it needed to define the accurate contour of each

\footnotetext{
${ }^{1}$ Center of Digital Dentistry, Peking University School and Hospital of Stomatology, Beijing, China.

${ }^{2}$ Department of Prosthodontics, Peking University School and Hospital of Stomatology, Beijing, China.

${ }^{3}$ National Engineering Laboratory for Digital and Material Technology of Stomatology, Beijing, China.

${ }^{4}$ Research Center of Engineering and Technology for Digital Dentistry of Ministry of Health, Beijing, China.

${ }^{5}$ Beijing Key Laboratory of Digital Stomatology, Beijing, China.

${ }^{6}$ Department of Orthodontics, Peking University School and Hospital of Stomatology, Beijing, China.
} 
tooth form CT slices. Hiew et al. (2010) proposed a graph cuts segmentation approach to obtain the 3D tooth model from CBCT images. The results showed the roots of the tooth had some non-dental tissues. Due to low image contrast, higher image noise and missing image boundaries, tooth segmentation in CBCT is difficult.

The present study explores a new semi-automatic method to segment the teeth from the CBCT images. For evaluation, the CBCT-segmented tooth model is compared with the light-scanned tooth surface model.

\section{MATERIAL AND METHOD}

2.1 Tools: (1) Software: ORS Visual 2.0 (ORS Company, Canada), Geomagic Studio 2012 \& Geomagic Qualify 2012 (3D Systems Company, America), (2) Hardware: structured white light scanner (IScan D104i, Imetric 3D SA, Switzerland).

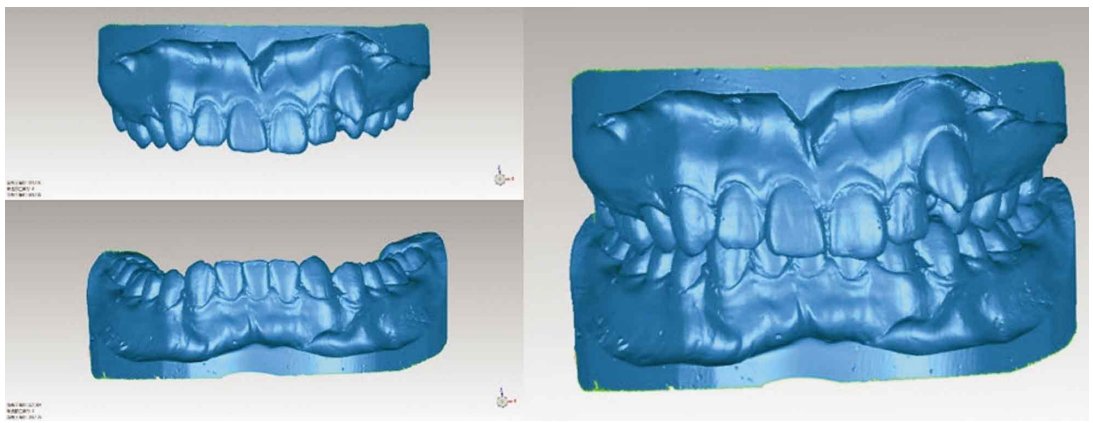

Fig.1. 3D data of the upper and lower dental casts and their relation to the jaw.

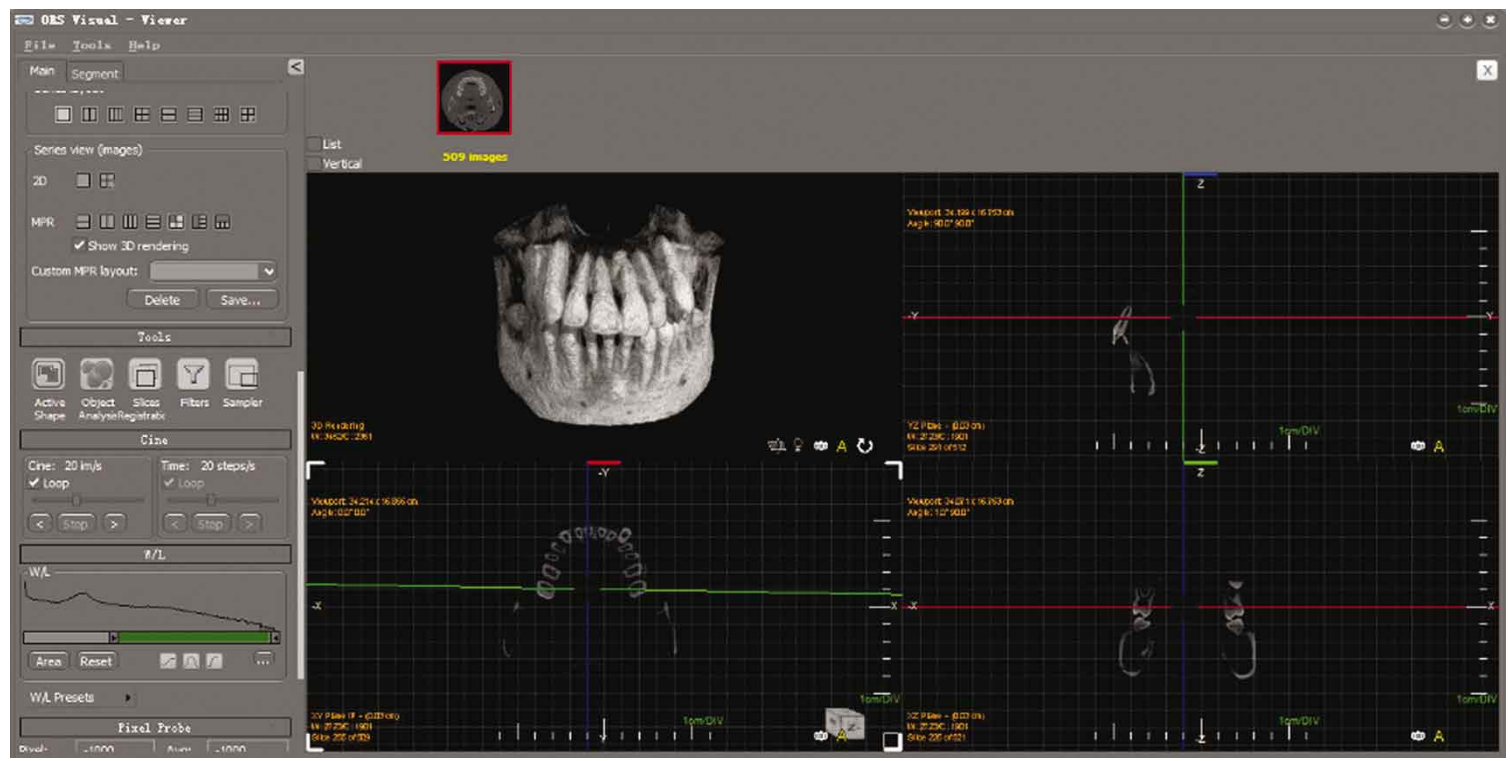

Fig. 2. Software interface of the ORS.

\section{2 data processing}

2.2.1 Data acquisition. One male patient was selected as the experimental subject. The maxillary CBCT scans were performed on the CBCT machine (DCT Pro; Vatech \& EWOO Group, South Korea). Images were obtained using the following protocol: field of view, $200 \times 190 \mathrm{~mm}^{2}$; 90 $\mathrm{kVp}, 144 \mathrm{~mA}$; scan time, $24 \mathrm{~s}$; voxel size, $0.4 \mathrm{~mm}$. Scanning conditions were constant with 360 rotation. All data were saved in the DICOM 3.0 format.

A structured white light scanner was used to obtain the 3D data for the upper, lower dental cast models and the relations to the jaw. The accuracy of the scanner was at $20 \mathrm{~mm}$. The scanned data was saved as 'Model_Upper.stl' and 'Model_Lower.stl' (Fig.1).

2.2.2 Segmentation. ORS Visual 2.0 software could provide a clinical workflow with selectable post-processing settings and real-time volumetric visualization, it also offers segmentation tools to visually isolate anatomy or features. We used this software to segment different teeth to different ROIs (Region of interests) and then analyze it. Then the data was saved as 'Teeth_upper.stl' and 'Teeth_Lower.stl'. 'Teeth_Upper.stl' and 'Teeth_Lower.stl' were merged into one data called 'Teeth.stl'. Software interface of the ORS software was showed in Figure 2. 
The proposed segmentation methodology consists of five stages: (a) loading data to the ORS software, (b) remove the data of the skull except the data upper and lower jaws, (c) based on gray value, segment teeth and save it as different ROIs, (d) combine different ROIs into an integrated mesh file, (e) smooth the mesh data. All the segmented teeth were shown in Figure 3.

2.2.3 Registration. The teeth data (which meant 'Teeth.stl') and the model data (which meant 'Model_Upper.stl' and 'Model_Lower.stl') were both saved in STL format. The registration was linear transformation, which include rotation, translation. With the software of Geomagic Studio
2012, using the 'Manual Registration' settings, fixed the teeth data, and aligned the models to teeth data, so the stl data of teeth and the models were in a same coordinate system. Results were shown in Figure 4.

2.2.4 Deviation analysis. A deviation analysis was done to compare the teeth data and the model data. Geomagic Qualify 2012 software was used to analyze differences between the teeth data and the model data. The teeth data was set as 'reference model' and the model data was set as 'test model'. The function of 'Deviation analysis' was used to analysis the distance from the Test to any point on the Reference.

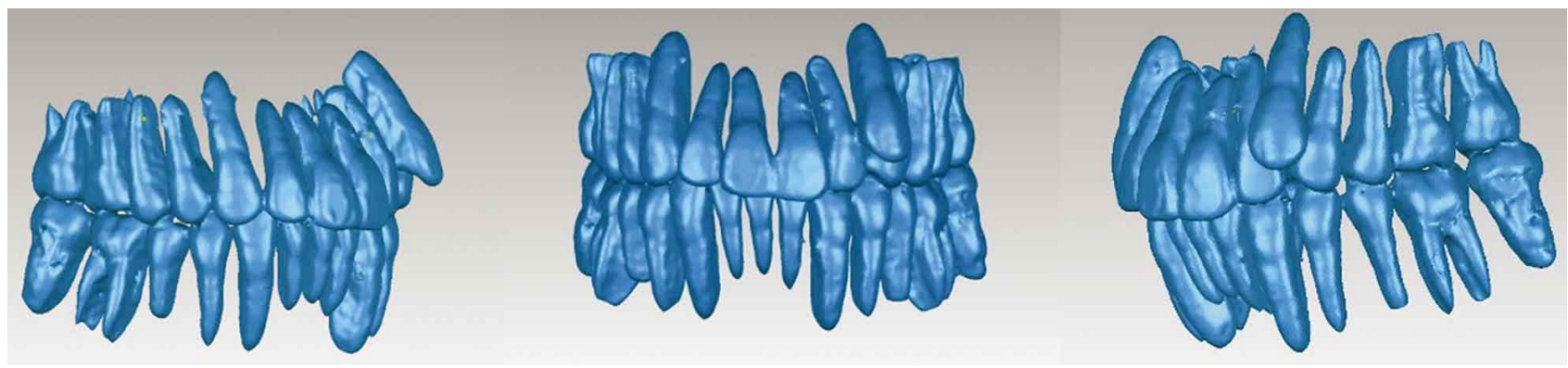

Fig. 3. Segmented teeth.
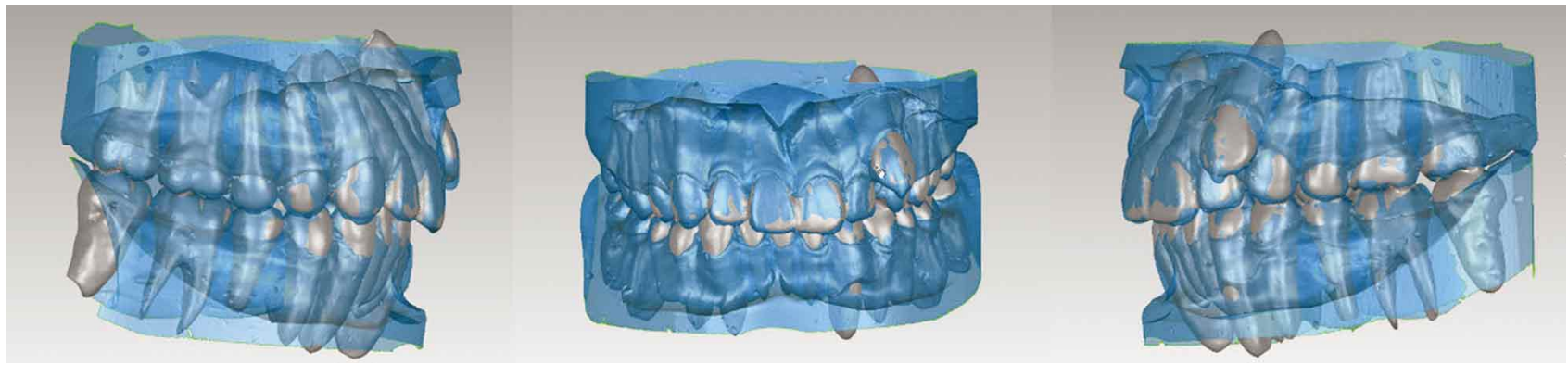

Fig. 4. Cast models and the teeth data after registration in Geomagic Studio 2012.

\section{RESULTS}

All teeth crown and root information can be accurately obtained using semi-automatic method to segment the tooth from the three-dimensional volume data which acquired from cone beam computed tomography. The method is simple to use and can be applied in orthodontic. The entire segmentation process took less than 30 minutes.

After registering the model data to teeth data, the deviation between them was then analyzed in Geomagic Studio. The actual values of the distance were -0.27 and $0.22 \mathrm{~mm}$; the measured Root Mean Square (RMS) value was $0.39 \mathrm{~mm}$, less than $0.4 \mathrm{~mm}$. The deviation analysis result was shown in Figure 5.

\section{DISCUSSION}

By this method, all teeth crown data can be obtained and showed in reverse engineering software and can be applied in orthodontic. The entire process took less than 30 minutes.

CBCT imaging could provide detailed images of the bone and be performed to evaluate diseases of the jaw, dentition, bony structures of the face, nasal cavity, nerve canals and sinuses. Although it couldn't provide the full diagnostic information available with conventional CT, particularly in evaluation of soft tissue structures such as muscles, lymph nodes, glands and nerves. But CBCT has the advantage of lower radiation exposure compared to conventional CT (Scarfe \& Farman, 2008). 


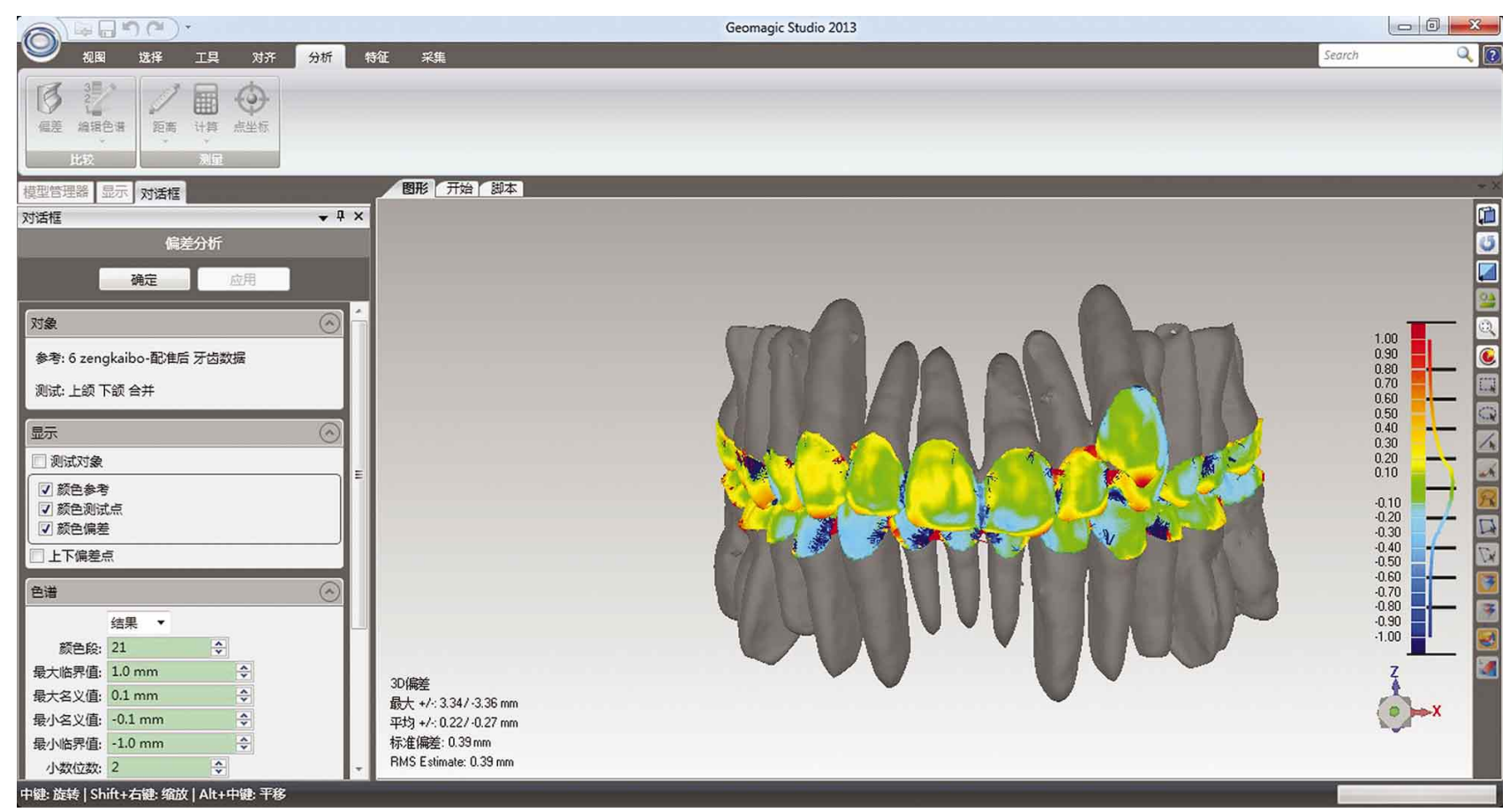

Fig. 5. The deviation analysis result.

In orthodontics, understanding the location of the root is very important for the orthodontic doctor. Diagnosis model based on crown cannot absolutely ensure the good alignment of roots without root exposure. It is necessary to construct the integrated model including root and crown for the diagnosis during tooth arrangement process. Tooth movement depended on the stress distribution in the periodontal ligament, whether it occurs through bone, or with bone were both important for the treatment (Melsen, 1999). Diagnosis model based only on crown which could not absolutely ensure the good alignment of roots without root exposure (Bovali et al., 2014; Park et al., 2016). It is necessary to construct the integrated model including root for diagnosis during tooth arrangement process. El-Timamy et al. (2016) used CBCT imaging and computer-aided manufacturing to produce stereolithographic trays for indirect-direct bonding, all the bracket positioning were based on the root axes, but the segmentation result with Mimics software still should be considered, and the segmentation accuracy of the teeth should be evaluated.

Threshold segmentation of CBCT was performed to generate 3D digital models (Machado, 2015). In order to validate the accuracy of the segmented results, the upper and lower dental cast models were scanned by a white light scanner. The accuracy of the scanner was $20 \mathrm{~mm}$. Than registration was done between the model data and teeth data, different registration method will affect the results, manual registration was used to manually align the two scans, 3 point-pairs on each of the data sets were selected. The deviation between them was analyzed in Geomagic Qualify. The actual values of the distance were -0.27 and $0.22 \mathrm{~mm}$; the measured Root Mean Square (RMS) value is $0.39 \mathrm{~mm}$, less than $0.4 \mathrm{~mm}$.

There are several drawbacks to the software that need to be improved. First, the whole segmentation process depends on commercial software and requires human interaction, which reduces efficiency. In the future, we hope special software can be developed to enable an automated process. The CBCT can automatically be reconstructed into three-dimensional images for different structure. Second, the method couldn't automatically determine the outer edge of the teeth margin. Root contour may be blurred because of the image noise and image intensity similarities between root and surrounding alveolar bone, especially in the posterior position, so the root extraction method should be improved and the operator should have a basic knowledge of dental anatomy. Third, it is impossible to intelligently identify teeth names and locations. Thus, further research is still underway to solve the above problems.

\section{CONCLUSION}

The semi-automatic method of segmenting the teeth from CBCT was realized. By the method, all teeth crown 
and root can be obtained. However, the whole design result needs to be precisely modified using the tools available in the two software packages to obtain a good result. Additionally, the entire design process was completed through human-computer interaction. Therefore, further studies are necessary to carry out and find an automated process software to make tooth segmentation design both simpler and faster.

YANG, H. \& WANG, S. Investigación sobre un método de segmentación y evaluación que combina características características morfológicas dentales. Int. J. Morphol., 38(5):1325-1329, 2020.

RESUMEN: El objetivo de este estudio fue explorar un nuevo método semiautomático para segmentar los dientes a partir de datos de volumen tridimensional adquiridos mediante escáner de tomografía computarizada de haz cónico (CBCT). Los modelos escaneados de moldes dentales se utilizan para evaluar la precisión de la segmentación. Para los datos CBCT se utilizó el software ORS, y basado en el valor gris, se usó un método semiautomático para segmentar los dientes los que posteriormente se guardaron en datos de formato STL. Los datos se ingresaron en el software Geomagic Studio. Los modelo dentales superior e inferior se escanearon con un escáner de luz blanca y la información también se guardó en formato STL. Después del registro y comparación de los datos del modelo y los datos de los dientes, la desviación entre estos se analizó en el programa Geomagic Qualify. Usando este método fue posible obtener de forma fácil todos los dientes y además aplicar en la biomecánica de ortodoncia. El proceso completo demoró menos de 30 minutos. El valor real medido de la raíz cuadrada media fue de $0,39 \mathrm{~mm}$, menos de $0,4 \mathrm{~mm}$. Este método puede segmentar los dientes mandibulares de forma rápida y confiable, con una mínima intervención del usuario. El método tiene una importancia crítica para la ortodoncia, simulaciones virtuales de las cirugías de la mandíbula y otras aplicaciones en estomatología.

PAlABRAS ClAVE: Tomografía computarizada de haz cónico; Escáner 3D; Segmentación; Ortodoncia digital.

\section{REFERENCES}

Bovali, E.; Kiliaridis, S \& Cornelis, M. A. Indirect vs direct bonding of mandibular fixed retainers in orthodontic patients: a single-center randomized controlled trial comparing placement time and failure over a 6-month period. Am. J. Orthod. Dentofacial Orthop., 146(6):701-8, 2014.

Cheng, C.; Cheng, X.; Dai, N.; Liu, Y.; Fan, Q.; Hou, Y. \& Jiang, X. Personalized orthodontic accurate tooth arrangement system with complete teeth model. J. Med. Syst., 39(9):84, 2015.

El-Timamy, A. M.; El-Sharaby, F. A.; Eid, F. H. \& Mostafa, Y. A. Threedimensional imaging for indirect-direct bonding. Am. J Orthod. Dentofacial Orthop., 149(6):928-31, 2016.

Gan, Y.; Xia, Z.; Xiong, J.; Zhao, Q.; Hu, Y. \& Zhang, J. Toward accurate tooth segmentation from computed tomography images using a hybrid level set model. Med. Phys., 42(1):14-27, 2015.
Heo, H. \& Chae, O. S. Segmentation of tooth in CT images for the 3D reconstruction of teeth. SPIE Proc. Vol. 5298, 2004. DOI: https:// www.doi.org/10.1117/12.526111

Hiew, L. T.; Ong, S. H. \& Foong, K. W. C. Tooth segmentation from conebeam CT using graph cut. Biopolis, Proceedings of the Second APSIPA Annual Summit and Conference, 2010. pp.272-5.

John, G. P.; Joy, T. E.; Mathew, J. \& Kumar, V. R. B. Applications of cone beam computed tomography for a prosthodontist. J. Indian Prosthodont. Soc., 16(1):3-7, 2016.

Kapila, S. D. \& Nervina, J. M. CBCT in orthodontics: assessment of treatment outcomes and indications for its use. Dentomaxillofac. Radiol., 44(1):20140282, 2015.

Kovisto, T.; Ahmad, M. \& Bowles, W. R. Proximity of the mandibular canal to the tooth apex. J. Endod., 37(3):311-5, 2011.

Liebregts, J. H. F.; Timmermans, M.; De Koning, M. J. J.; Bergé, S. J. \& Maal, T. J. J. Three-dimensional facial simulation in bilateral sagittal split osteotomy: a validation study of 100 patients. J. Oral Maxillofac Surg., 73(5):961-70, 2015.

Machado, G. L. CBCT imaging - A boon to orthodontics. Saudi Dent. J., 27(1):12-21, 2015.

Melsen, B. Biological reaction of alveolar bone to orthodontic tooth movement. Angle Orthod., 69(2):151-8, 1999.

Merrett, S. J.; Drage, N. A. \& Durning, P. Cone beam computed tomography: a useful tool in orthodontic diagnosis and treatment planning. J. Orthod., 36(3):202-10, 2009.

Park, J. H.; Tai, K. \& Owtad, P. 3-Dimensional cone-beam computed tomography superimposition: A review. Semin. Orthod., 21(4):263-73, 2015.

Park, J. H.; Tai, K. \& Sato, Y. Orthodontic treatment of a patient with severe crowding and unilateral fracture of the mandibular condyle. Am. J. Orthod. Dentofacial Orthop., 149(6):899-911, 2016.

Porciúncula, G. M.; Koerich, L.; Eidson, L.; Gandini Junior, L. G. \& Gonçalves, J. R. Can cone-beam computed tomography superimposition help orthodontists better understand relapse in surgical patients? Am. J. Orthod. Dentofacial Orthop., 146(5):641-54, 2014.

Scarfe, W. C. \& Farman, A. G. What is cone-beam CT and how does it work?. Dent. Clin. North Am., 52(4):707-30, 2008.

Shahbazian, M.; Jacobs, R.; Wyatt, J.; Denys, D.; Lambrichts, I.; Vinckier, F. \& Willems, G. Validation of the cone beam computed tomographybased stereolithographic surgical guide aiding autotransplantation of teeth: clinical case-control study. Oral Surg. Oral Med. Oral Pathol. Oral Radiol., 115(5):667-75, 2013.

\section{Corresponding author:}

Huifang Yang

No. 22 South Street

Zhongguancun Haidian District

Beijing, 100081

CHINA

Email: yhfyanghuifang@126.com

Received: 10-04-2020

Accepted: 10-05-2020 